\title{
A Comprehensive Study on Pyrolysis Mechanism of Substituted $\beta-O-4$ Type Lignin Dimers
}

\author{
Xiaoyan Jiang, Qiang Lu *, Bin Hu, Ji Liu, Changqing Dong and Yongping Yang \\ National Engineering Laboratory for Biomass Power Generation Equipment, North China Electric Power \\ University, Beijing 102206, China; jiangxiaoyan@ncepu.edu.cn (X.J.); hubin@ncepu.edu.cn (B.H.); \\ liujipower@ncepu.edu.cn (J.L.); dongcq@ncepu.edu.cn (C.D.); yyp@ncepu.edu.cn (Y.Y.) \\ * Correspondence: qlu@ncepu.edu.cn; Tel.: +86-10-6177-2030
}

Received: 14 October 2017; Accepted: 5 November 2017; Published: 9 November 2017

\begin{abstract}
In order to understand the pyrolysis mechanism of $\beta-O-4$ type lignin dimers, a pyrolysis model is proposed which considers the effects of functional groups (hydroxyl, hydroxymethyl and methoxyl) on the alkyl side chain and aromatic ring. Furthermore, five specific $\beta-O-4$ type lignin dimer model compounds are selected to investigate their integrated pyrolysis mechanism by density functional theory (DFT) methods, to further understand and verify the proposed pyrolysis model. The results indicate that a total of 11 pyrolysis mechanisms, including both concerted mechanisms and homolytic mechanisms, might occur for the initial pyrolysis of the $\beta-O-4$ type lignin dimers. Concerted mechanisms are predominant as compared with homolytic mechanisms throughout unimolecular decomposition pathways. The competitiveness of the eleven pyrolysis mechanisms are revealed via different model compounds, and the proposed pyrolysis model is ranked in full consideration of functional groups effects. The proposed pyrolysis model can provide a theoretical basis to predict the reaction pathways and products during the pyrolysis process of $\beta-O-4$ type lignin dimers.
\end{abstract}

Keywords: lignin model compound; $\beta-O-4$ linkage; functional group; pyrolysis mechanism; density functional theory

\section{Introduction}

Lignin is the most abundant renewable aromatic biopolymer in nature, biosynthesized through polymerization of three basic monolignols, i.e., $p$-coumaryl, coniferyl, and sinapyl alcohols which are interlinked by $\mathrm{C}-\mathrm{O}$ bonds (e.g., $\beta-O-4, \alpha-O-4$ and $4-O-5$ ) and $\mathrm{C}-\mathrm{C}$ bonds (e.g., $\beta-1, \beta-5$ and 5-5) [1-4]. Apart from different linkages, there are various functional groups on the alkyl side chain and aromatic ring of the lignin basic units, including methoxyl, hydroxyl, hydroxymethyl, carbonyl and more [5-7]. Among them, methoxyl, hydroxyl and hydroxymethyl groups are native substituents while others (such as carbonyls) are non-native and chemically modified via the oxidization of the $\mathrm{OH}$ group on the $\mathrm{C}_{\alpha}$ or $\mathrm{C}_{\gamma}$ positions [1,6]. Therefore, lignin is the most complex component among the three basic components of lignocellulosic biomass. Pyrolysis is a promising thermo-chemical conversion method for the utilization of lignocellulosic biomass materials [8-10], through which lignin can be decomposed to form various value-added aromatic compounds [9,11,12]. However, conventional pyrolysis is a non-selective process, and it has difficulty selectively controlling the lignin decomposition process towards specific aromatic compounds. In order to develop more efficient selective pyrolysis techniques, lignin pyrolysis mechanism and products formation pathways should be deeply uncovered to help provide a theoretical basis for directional control of the lignin pyrolysis process. Density functional theory (DFT) method is an effective tool to reveal the lignin pyrolysis mechanism at a micro level [13-16]. 
Due to the complex structure of natural lignin, lignin-based model compounds are widely used to investigate the pyrolysis mechanism of lignin. Considering that the $\beta-O-4$ linkage is dominant, accounting for about half of the linkages in lignin, $\beta-O-4$ type lignin dimer model compounds are typically selected for theoretical studies [13,17-19]. Previous research has investigated the pyrolysis mechanism of various $\beta-O-4$ type lignin dimer model compounds containing different functional groups on the alkyl side chain and aromatic ring [20,21]. Beste et al. [20] considered that phenethyl phenyl ether (PPE) mainly underwent $\mathrm{C}_{\beta}-\mathrm{O}$ bond and $\mathrm{C}_{\alpha}-\mathrm{C}_{\beta}$ bond homolytic cleavage reactions during the primary pyrolysis process. However, Elder et al. [21] found that two concerted reactions (retro-ene fragmentation and Maccoll elimination) were prior to $\mathrm{C}_{\beta}-\mathrm{O}$ bond and $\mathrm{C}_{\alpha}-\mathrm{C}_{\beta}$ bond homolytic cleavage reactions, and the energy barrier of retro-ene fragmentation was lower than that of Maccoll elimination. Currently, it is widely recognized that concerted reactions and homolytic reactions are coexisting during the lignin pyrolysis process $[19,22]$. Nevertheless, functional groups on the alkyl side chain and aromatic ring may have great effects on lignin pyrolysis mechanism. Basically, they can influence the bond dissociation energies (BDEs) of major bonds $[5,6,17]$ and enrich the reaction pathways, including both concerted reaction pathways and homolytic reaction pathways $[13,23]$. Some experimental studies have also confirmed that functional groups could affect the thermal behavior and product distribution of lignin [24-27]. Kawamoto et al. [24,27] studied the effect of hydroxyl groups at $C_{\alpha}$ and $C_{\gamma}$ positions of the alkyl side chain on pyrolytic reactions of $\beta-O-4$ type lignin dimer model compounds. Results suggested that the hydrogen bond between the two hydroxyl groups would affect the reaction sequences of $C_{\gamma}$-elimination and $C_{\beta}-O$ bond homolytic cleavage, and further influence the product distribution. Britt et al. [28] found that the methoxyl group on the aromatic ring would weaken the $\mathrm{C}_{\beta}-\mathrm{O}$ bond and make it easier to undergo homolytic reaction. Furthermore, the methoxyl group would promote $\mathrm{O}-\mathrm{CH}_{3}$ bond homolytic cleavage [23,29], and the hydroxyl group on the alkyl side chain would transform into ketone or accelerate the dehydration reaction [13]. However, there are few comprehensive studies focusing on the effects of these substituents on the unimolecular decomposition pathways of lignin.

Due to the limitation of previous studies, a pyrolysis model for $\beta-O-4$ type lignin dimers is proposed which takes the effects of native substituents (hydroxyl, hydroxymethyl and methoxyl) located on alkyl side chain and aromatic ring into consideration. The above three substituents are very common and characteristic in the natural lignin structure [6,17]. Furthermore, five specific $\beta-O-4$ type lignin dimer model compounds containing hydroxyl, hydroxymethyl and methoxyl groups are selected to reveal their pyrolysis mechanism by DFT calculation and to understand the proposed pyrolysis model.

\section{Results}

\subsection{Pyrolysis Model for $\beta-O-4$ Type Lignin Dimers}

Based on the possible pyrolysis reactions and previous studies [13,23,29], a pyrolysis model for $\beta-O-4$ type lignin dimers (LD) is proposed as shown in Figure 1, which considers the effects of hydroxyl, hydroxymethyl, and methoxyl groups on pyrolysis pathways. Mechanisms 1-9 are concerted reactions, while mechanisms 10 and 11 are homolytic reactions. Among them, mechanisms 1, 2 and 11 are three basic pyrolysis mechanisms for all $\beta-O-4$ type lignin dimers regardless of substituents. They are Maccoll elimination, retro-ene fragmentation and $\mathrm{C}_{\beta}-\mathrm{O}$ bond homolytic cleavage, respectively [21].

When the methoxyl group is located on the aromatic ring of $\beta-O-4$ type lignin dimer model compounds, mechanisms 3 and 10 will take place. Mechanism 3 is another retro-ene fragmentation. The $\mathrm{H}$ atom at $\mathrm{C}_{\alpha}$ position transfers to aromatic carbon atom where the methoxyl group is located. Mechanism 10 is $\mathrm{O}-\mathrm{CH}_{3}$ bond homolytic cleavage reaction. Britt et al. [29] found that $\mathrm{O}-\mathrm{CH}_{3}$ bond as well as $\mathrm{C}_{\beta}-\mathrm{O}$ bond were the weakest bonds in lignin which were easy to break during the primary pyrolysis process. 
When the hydroxyl group substitutes at $C_{\alpha}$ position, mechanisms 4, 5 and 6 will occur. Mechanism 4 is a dehydration reaction. The hydroxyl group at $C_{\alpha}$ position and the $H$ atom at $C_{\beta}$ position undergo dehydration reaction to form a compound containing an unsaturated $\mathrm{C}=\mathrm{C}$ double bond. In mechanisms 5 and 6 , the $\mathrm{H}$ atom of the hydroxyl group at $\mathrm{C}_{\alpha}$ position will transfer to the oxygen atom of ether bond and $C_{\beta}$ position meanwhile rupturing the $C_{\beta}-O$ and $C_{\alpha}-C_{\beta}$ bonds, respectively.

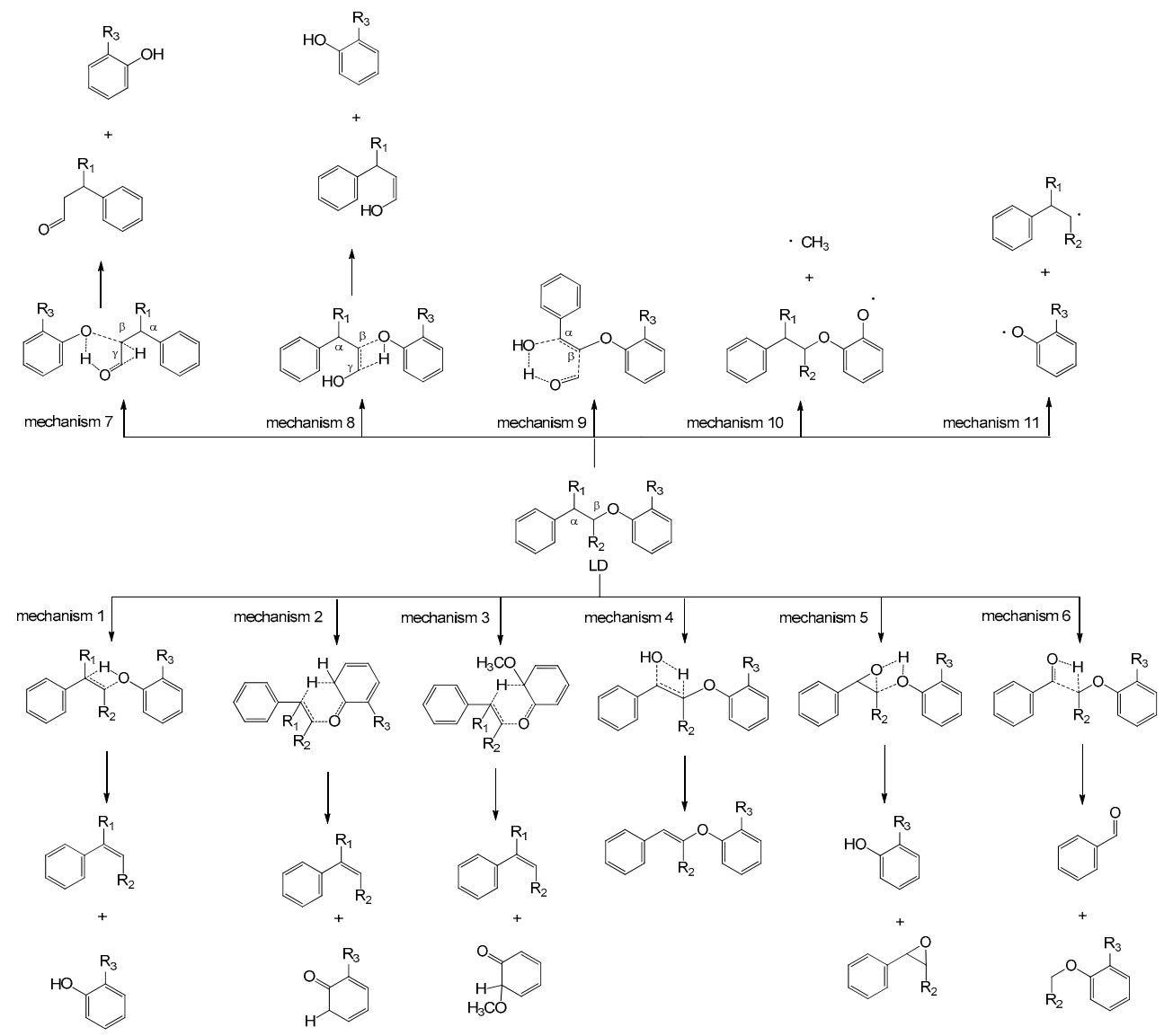

Figure 1. Pyrolysis model for $\beta-O-4$ type lignin dimers (LD).

When the hydroxymethyl group substitutes at $C_{\beta}$ position, mechanisms 7 and 8 will take place through which the $\mathrm{H}$ atoms of hydroxyl group and $\mathrm{C}_{\gamma}$ position will transfer to the oxygen atom of ether bond with the rupture of $\mathrm{C}_{\beta}-\mathrm{O}$ bond, respectively. When the hydroxyl and hydroxymethyl groups are located on the $C_{\alpha}$ and $C_{\beta}$ positions of a $\beta-O-4$ type lignin dimer model compound, it will undergo mechanism 9 to form water, formaldehyde and a compound with an unsaturated $\mathrm{C}=\mathrm{C}$ double bond.

The pyrolysis model in Figure 1 depicts possible pyrolysis pathways of $\beta-O-4$ type lignin dimers during the primary pyrolysis process, which just provides the basic information to predict possible pyrolytic products formed in the subsequent pyrolysis process. In the following section, five specific model compounds will be employed to investigate their detailed pyrolysis pathways based on this model, to illustrate the competitiveness of possible pyrolytic pathways.

\subsection{Pyrolysis Mechanism of $\beta-O-4$ Type Lignin Dimers Based on the Pyrolysis Model}

In order to further understand the proposed pyrolysis model and explore the effects of hydroxyl, hydroxymethyl and methoxyl groups on the unimolecular decomposition pathways of $\beta-O-4$ type lignin dimers, five specific model compounds are selected to investigate their detailed pyrolysis mechanisms and pathways, including phenethyl phenyl ether (PPE), 1-methoxy-2-phenethoxybenzene (o- $\left.\mathrm{CH}_{3} \mathrm{O}-\mathrm{PPE}\right), 2$-phenoxy-1-phenylethanol $(\alpha-\mathrm{OH}-\mathrm{PPE})$, 
2-phenoxy-3-phenylpropan-1-ol ( $\beta$ - $\left.\mathrm{CH}_{2} \mathrm{OH}-\mathrm{PPE}\right)$, and 2-(2-methoxyphenoxy)-1-phenylpropane1,3-diol $\left(\alpha-\mathrm{OH}-\beta-\mathrm{CH}_{2} \mathrm{OH}-o-\mathrm{CH}_{3} \mathrm{O}-\mathrm{PPE}\right)$. The detailed integrated pyrolysis mechanism of $\alpha-\mathrm{OH}-\beta-\mathrm{CH}_{2} \mathrm{OH}-\mathrm{o}-\mathrm{CH}_{3} \mathrm{O}-\mathrm{PPE}$ is discussed below and categorized into concerted mechanisms and homolytic mechanisms. Others are shown in the Supplementary Materials (Figures S1-S4).

\subsubsection{Concerted Mechanisms of Model Compound $\alpha-\mathrm{OH}-\beta-\mathrm{CH}_{2} \mathrm{OH}-o-\mathrm{CH}_{3} \mathrm{O}-\mathrm{PPE}$}

Pyrolysis of model compound $\alpha-\mathrm{OH}-\beta-\mathrm{CH}_{2} \mathrm{OH}-o-\mathrm{CH}_{3} \mathrm{O}-\mathrm{PPE}$ involves nine possible concerted mechanisms (mechanisms 1-9 in Figure 1) due to the presence of the substituents. The possible reaction pathways following the nine concerted mechanisms are designed in Figure 2 and the potential energy profile along the pathways is shown in Figure 3.

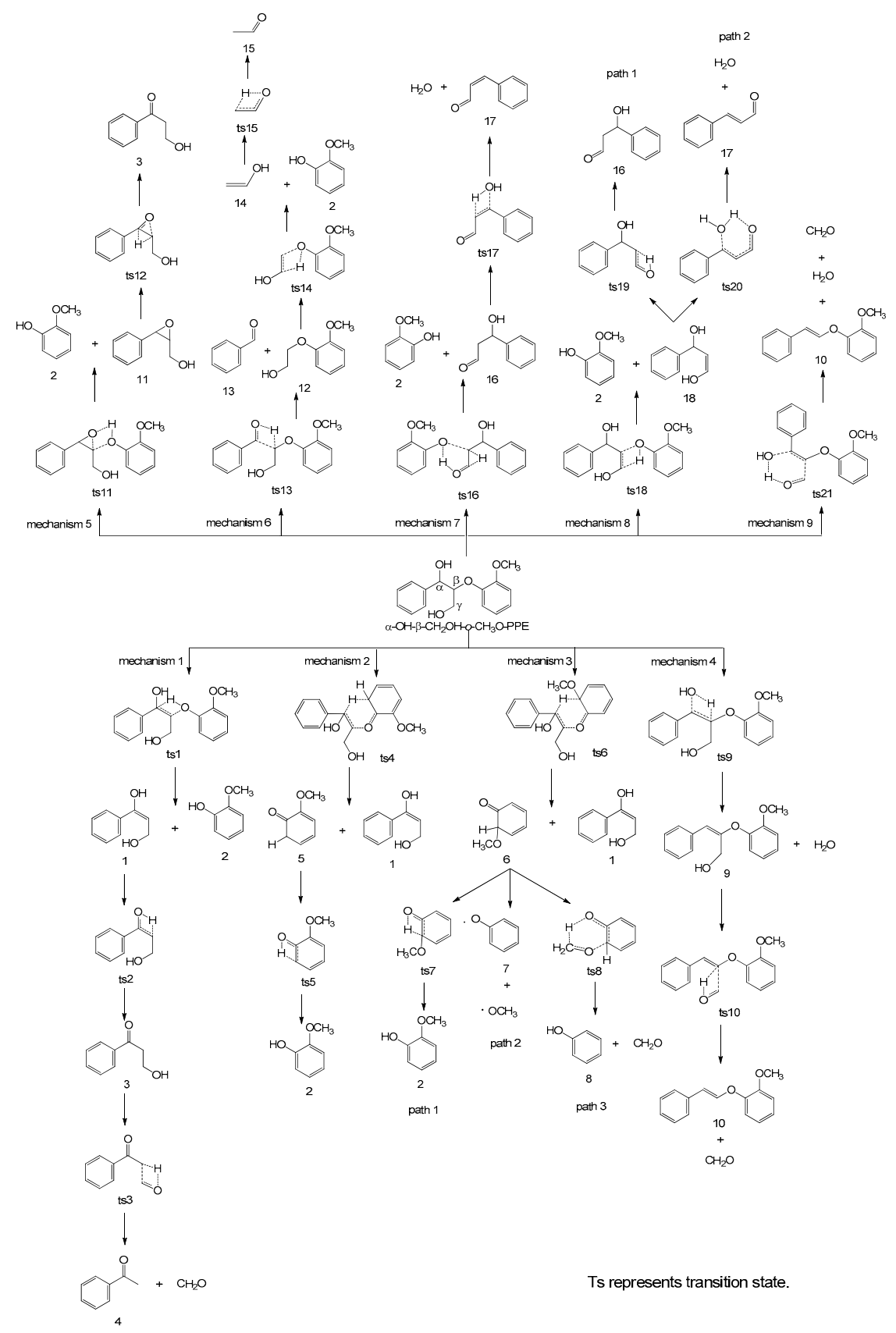

Figure 2. Possible reaction pathways based on concerted mechanisms $1-9$ of the $\beta-O-4$ type lignin dimer model compound $\alpha-\mathrm{OH}-\beta-\mathrm{CH}_{2} \mathrm{OH}-o-\mathrm{CH}_{3} \mathrm{O}-\mathrm{PPE}$. 

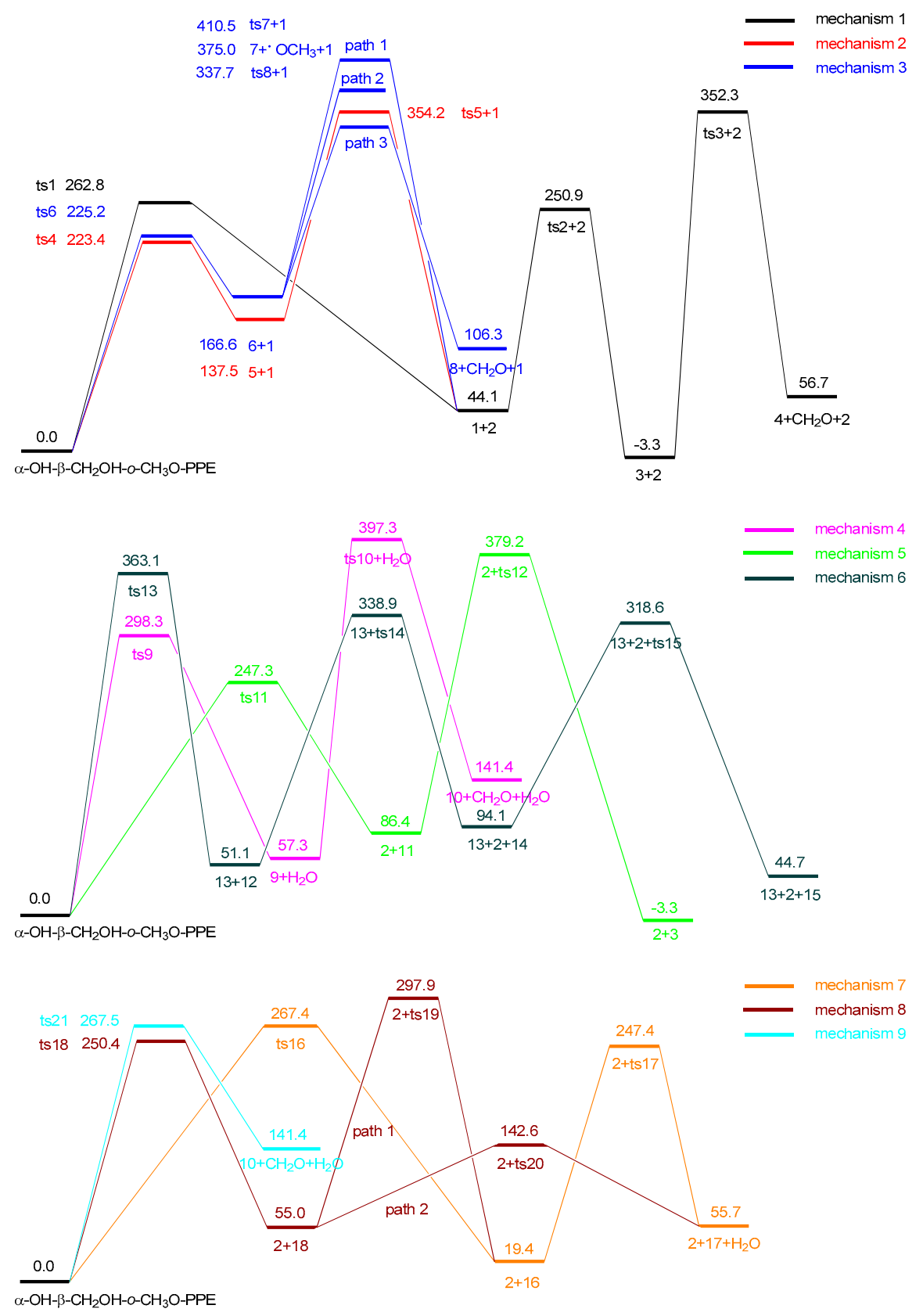

Figure 3. Potential energy profile along the reaction pathways based on concerted mechanisms 1-9.

Mechanisms 1 and 2 are the two common concerted mechanisms existing in the pyrolysis process of all $\beta-\mathrm{O}-4$ type lignin dimers [21]. In concerted mechanism $1, \alpha-\mathrm{OH}-\beta-\mathrm{CH}_{2} \mathrm{OH}-o-\mathrm{CH}_{3} \mathrm{O}-\mathrm{PPE}$ undergoes Maccoll elimination through a four-membered ring transition state ts1 with an energy barrier of $262.8 \mathrm{~kJ} / \mathrm{mol}$. The $\mathrm{H}$ atom at $\mathrm{C}_{\alpha}$ position transfers to the oxygen atom of the ether bond. Simultaneously, the $\mathrm{C}_{\beta}-\mathrm{O}$ bond ruptures and the $\mathrm{C}_{\alpha}-\mathrm{C}_{\beta}$ bond transforms into $\mathrm{C}=\mathrm{C}$ double bond, forming intermediate $\mathbf{1}$ and product $\mathbf{2}$ (2-methoxyphenol). Intermediate $\mathbf{1}$ contains an extremely unstable enol structure which easily undergoes isomerization through transition state ts 2 to generate product 3 (3-hydroxy-1-phenylpropan-1-one) with a ketone structure, overcoming an energy barrier of $206.8 \mathrm{~kJ} / \mathrm{mol}$. Product 3 with the hydroxymethyl group at $C_{\beta}$ position may undergo a secondary reaction via a four-membered ring transition state ts 3 to form product 4 (acetophenone) and formaldehyde, overcoming an energy barrier of $355.6 \mathrm{~kJ} / \mathrm{mol}$. 
In concerted mechanism 2, $\alpha-\mathrm{OH}-\beta-\mathrm{CH}_{2} \mathrm{OH}-o-\mathrm{CH}_{3} \mathrm{O}-\mathrm{PPE}$ firstly undergoes retro-ene fragmentation through a six-membered ring transition state ts 4 to form intermediates $\mathbf{1}$ and $\mathbf{5}$ with an energy barrier of $223.4 \mathrm{~kJ} / \mathrm{mol}$, which is lower than the energy barrier of ts 1 in concerted mechanism 1. Intermediate 5 then undergoes intramolecular hydrogen transfer reaction through transition state ts 5 to form product 2 (2-methoxyphenol) with an energy barrier of $216.7 \mathrm{~kJ} / \mathrm{mol}$. Intermediate 1 will transform into product 3 (3-hydroxy-1-phenylpropan-1-one) following the reaction pathway in concerted mechanism 1.

Concerted mechanism 3 is similar to concerted mechanism 2. The only difference is that the $H$ atom at $C_{\alpha}$ position transfers to the aromatic carbon atom where methoxyl group is located through transition state ts $\mathbf{6}$ with an energy barrier of $225.2 \mathrm{~kJ} / \mathrm{mol}$, forming intermediates $\mathbf{1}$ and $\mathbf{6}$. The energy barrier of ts $\mathbf{6}$ is close to that of ts 4 in concerted mechanism 2. Intermediate $\mathbf{6}$ has three possible subsequent reaction pathways. In path 1 , it undergoes intramolecular hydrogen transfer reaction through transition state ts7 to form product 2 (2-methoxyphenol) with an energy barrier of $243.9 \mathrm{~kJ} / \mathrm{mol}$. Due to the existence of the methoxyl group, intermediate 6 can also undergo paths 2 and 3 . In path 2, it undergoes demethoxylation to generate radical 7 with an energy barrier of $208.4 \mathrm{~kJ} / \mathrm{mol}$. In path 3 , it undergoes intramolecular hydrogen transfer reaction through a six-membered ring transition state ts 8 to form product 8 (phenol) and formaldehyde, overcoming the lowest energy barrier of $171.1 \mathrm{~kJ} / \mathrm{mol}$. Therefore, path 3 is most likely to occur among the three possible subsequent reaction pathways in concerted mechanism 3.

Mechanisms 4-6 are closely related to the hydroxyl group at $C_{\alpha}$ position. In concerted mechanism 4 , the hydroxyl group at $\mathrm{C}_{\alpha}$ position and the $\mathrm{H}$ atom at $\mathrm{C}_{\beta}$ position of $\alpha-\mathrm{OH}-\beta-\mathrm{CH}_{2} \mathrm{OH}-\mathrm{o}-\mathrm{CH}_{3} \mathrm{O}-\mathrm{PPE}$ undergo dehydration reaction through a four-membered ring transition state ts 9 to form intermediate 9, overcoming an energy barrier of $298.3 \mathrm{~kJ} / \mathrm{mol}$. Then intermediate 9 will lose a molecule of formaldehyde through transition state $\mathbf{t s} \mathbf{1 0}$ to form product 10 (1-methoxy-2-(styryloxy)benzene) with an energy barrier of $340.0 \mathrm{~kJ} / \mathrm{mol}$ due to the hydroxymethyl group at $C_{\beta}$ position.

In concerted mechanism $5, \alpha-\mathrm{OH}-\beta-\mathrm{CH}_{2} \mathrm{OH}-o-\mathrm{CH}_{3} \mathrm{O}-\mathrm{PPE}$ goes through transition state ts11 to form product 2 (2-methoxyphenol) and intermediate 11 with an energy barrier of $247.3 \mathrm{~kJ} / \mathrm{mol}$, through which the $\mathrm{H}$ atom of the hydroxyl group at $\mathrm{C}_{\alpha}$ position transfers to the oxygen atom of the ether bond. Intermediate $\mathbf{1 1}$ then undergoes transition state ts 12 to form product 3 (3-hydroxy-1-phenylpropan-1-one) with an energy barrier of $292.8 \mathrm{~kJ} / \mathrm{mol}$.

In concerted mechanism 6 , the $\mathrm{H}$ atom of the hydroxyl group at $\mathrm{C}_{\alpha}$ position of $\alpha-\mathrm{OH}-\beta-\mathrm{CH}_{2} \mathrm{OH}-o-\mathrm{CH}_{3} \mathrm{O}-\mathrm{PPE}$ transfers to $\mathrm{C}_{\beta}$ position and the $\mathrm{C}_{\alpha}-\mathrm{C}_{\beta}$ bond breaks to form intermediate 12 and product 13 (benzaldehyde) with an energy barrier of $363.1 \mathrm{~kJ} / \mathrm{mol}$. Intermediate 12 goes through a four membered ring transition state ts 14 to form product $\mathbf{2}$ (2-methoxyphenol) and intermediate 14 with an energy barrier of $287.8 \mathrm{~kJ} / \mathrm{mol}$. Intermediate 14 will undergo isomerization through transition state ts15 to form product 15 (acetaldehyde) with an energy barrier of $224.5 \mathrm{~kJ} / \mathrm{mol}$.

Mechanisms 7 and 8 are closely related to the hydroxymethyl group at $C_{\beta}$ position. In concerted mechanism 7 , the $\mathrm{H}$ atom of the hydroxyl group at $\mathrm{C}_{\gamma}$ position of $\alpha-\mathrm{OH}-\beta-\mathrm{CH}_{2} \mathrm{OH}-\mathrm{o}-\mathrm{CH}_{3} \mathrm{O}-\mathrm{PPE}$ transfers to the oxygen atom of the ether bond through transition state ts 16 to generate product 2 (2-methoxyphenol) and intermediate 16, overcoming an energy barrier of $267.4 \mathrm{~kJ} / \mathrm{mol}$. The hydroxyl group at $C_{\alpha}$ position and the $H$ atom at $C_{\beta}$ position of intermediate 16 undergo dehydration reaction with an energy barrier of $228.0 \mathrm{~kJ} / \mathrm{mol}$, forming product 17 (3-phenylacrylaldehyde).

In concerted mechanism $8, \alpha-\mathrm{OH}-\beta-\mathrm{CH}_{2} \mathrm{OH}-o-\mathrm{CH}_{3} \mathrm{O}-\mathrm{PPE}$ goes through transition state ts 18 to generate product 2 (2-methoxyphenol) and intermediate 18 with an energy barrier of $250.4 \mathrm{~kJ} / \mathrm{mol}$, through which the $\mathrm{H}$ atom at $\mathrm{C}_{\gamma}$ position transfers to the oxygen atom of the ether bond. The enol structure of intermediate $\mathbf{1 8}$ is easy to undergo isomerization through transition state ts19 to form intermediate 16 with an energy barrier of $242.9 \mathrm{~kJ} / \mathrm{mol}$. Then intermediate $\mathbf{1 6}$ will transform into product 17 (3-phenylacrylaldehyde) following the reaction pathway in concerted mechanism 7. In addition to the isomerization reaction, intermediate $\mathbf{1 8}$ can also undergo dehydration reaction through a six-membered ring transition state ts20 to form product 17 (3-phenylacrylaldehyde) with 
an energy barrier of $87.6 \mathrm{~kJ} / \mathrm{mol}$, which is much lower than the energy barrier of ts19. Therefore, it is much easier for intermediate $\mathbf{1 8}$ to go through the dehydration reaction to form product $\mathbf{1 7}$.

Concerted mechanism 9 is related to both the hydroxyl group at $\mathrm{C}_{\alpha}$ position and the hydroxymethyl group at $\mathrm{C}_{\beta}$ position. $\alpha-\mathrm{OH}-\beta-\mathrm{CH}_{2} \mathrm{OH}-\mathrm{o}-\mathrm{CH}_{3} \mathrm{O}-\mathrm{PPE}$ undergoes a six membered ring transition state ts $\mathbf{2 1}$ to directly form product $\mathbf{1 0}$ (1-methoxy-2-(styryloxy)benzene) with an energy barrier of $267.5 \mathrm{~kJ} / \mathrm{mol}$, losing a molecule of water and formaldehyde.

According to the above results, the sequence of energy barriers of the above nine concerted mechanisms is as follows: mechanism $2<$ mechanism $3<$ mechanism $5<$ mechanism $8<$ mechanism 1 $<$ mechanism $7<$ mechanism $9<$ mechanism $4<$ mechanism 6 . The primary aromatic products are 2 (2-methoxyphenol), 3 (3-hydroxy-1-phenylpropan-1-one), 8 (phenol), 17 (3-phenylacrylaldehyde), 10 (1-methoxy-2-(styryloxy)benzene) and $\mathbf{1 3}$ (benzaldehyde), as well as some low molecular compounds (formaldehyde, water and acetaldehyde). As shown in Figure 3, these products are formed via different mechanisms. Products 2 and 3 can be formed from mechanisms 1, 2 and 5, among which the energy barrier of mechanism 2 is the lowest. Mechanism 8 is superior to mechanism 7 to form product 17, and mechanism 9 is superior to mechanism 4 to form product 10. In regard to products 8 and $\mathbf{1 3}$, their formation pathways are attributed to mechanisms 3 and 6, respectively.

\subsubsection{Homolytic Mechanisms of Model Compound $\alpha-\mathrm{OH}-\beta-\mathrm{CH}_{2} \mathrm{OH}-o-\mathrm{CH}_{3} \mathrm{O}-\mathrm{PPE}$}

The possible homolytic cleavage reactions of the major bonds and their corresponding BDEs are illustrated in Figure 4. Compared with other homolytic cleavage reactions, the $\mathrm{O}-\mathrm{CH}_{3}$ bond homolytic cleavage (mechanism 10) has the lowest $\mathrm{BDE}$, followed by the $\mathrm{C}_{\beta}-\mathrm{O}$ bond homolytic cleavage (mechanism 11), indicating that mechanisms 10 and 11 are the two favorable homolytic mechanisms of lignin model compound $\alpha-\mathrm{OH}-\beta-\mathrm{CH}_{2} \mathrm{OH}-o-\mathrm{CH}_{3} \mathrm{O}-\mathrm{PPE}$. Other homolytic cleavage reactions can hardly take place due to the high BDEs. Such results also reflect that the proposed pyrolysis model in Figure 1 is reasonable. Except for concerted mechanisms 4 and 6, the activation energies of other concerted mechanisms are lower than the BDEs of homolytic mechanisms during the primary pyrolysis process. Hence, it can be concluded that concerted mechanisms should be mainly responsible for the pyrolysis process, while homolytic mechanisms are less important than concerted mechanisms. The subsequent pyrolysis pathways based on mechanisms 10 and 11 are discussed below.

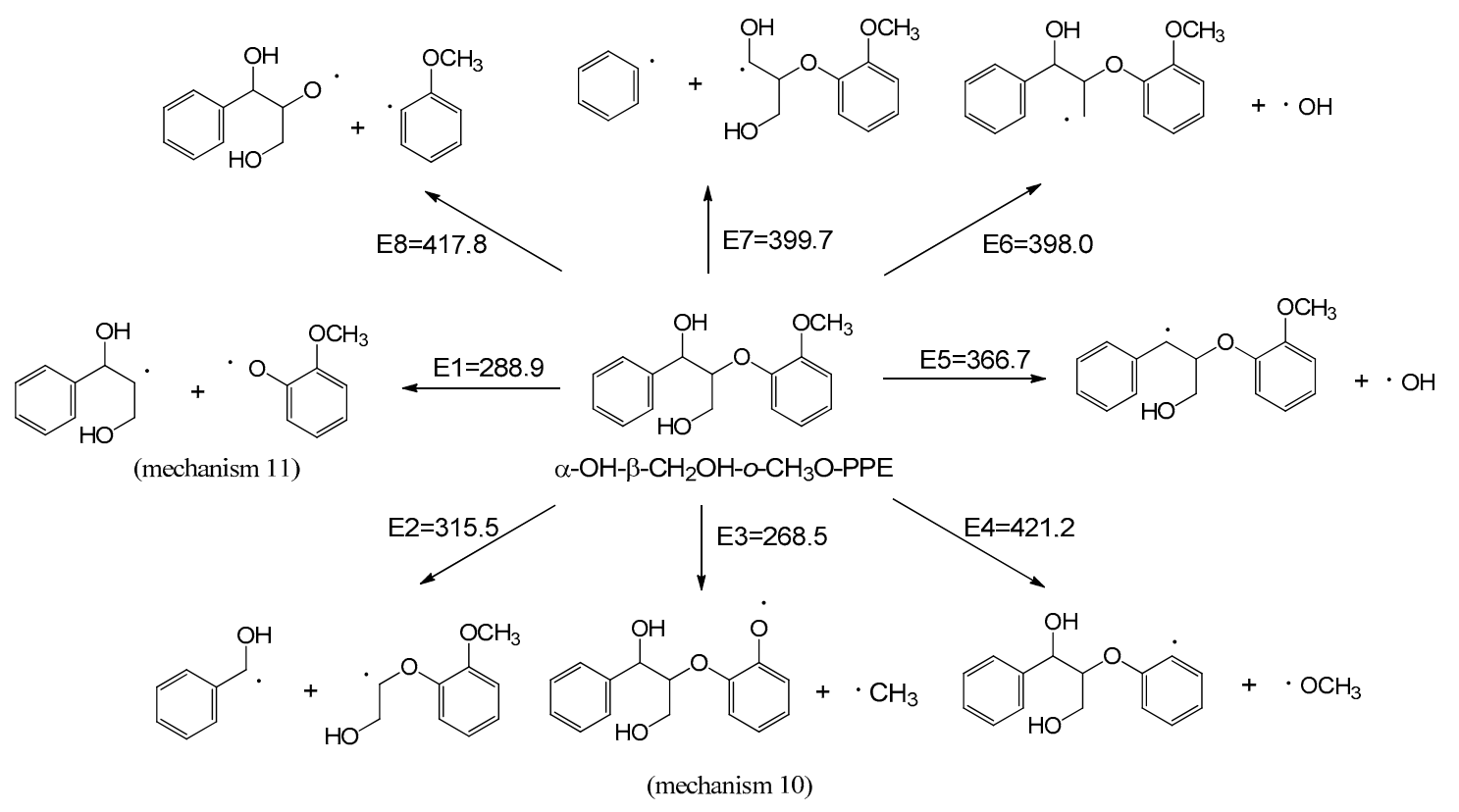

Figure 4. Bond dissociation energies of the major bonds in lignin model compound $\alpha-\mathrm{OH}-\beta-\mathrm{CH}_{2} \mathrm{OH}-\mathrm{o}-\mathrm{CH}_{3} \mathrm{O}-\mathrm{PPE}$ (unit: $\mathrm{kJ} / \mathrm{mol}$ ). 
In homolytic mechanism 10, $\alpha-\mathrm{OH}-\beta-\mathrm{CH}_{2} \mathrm{OH}-\mathrm{o}-\mathrm{CH}_{3} \mathrm{O}-\mathrm{PPE}$ undergoes $\mathrm{O}-\mathrm{CH}_{3}$ bond homolytic cleavage to form radical 19 and methyl radical with an energy barrier of $268.5 \mathrm{~kJ} / \mathrm{mol}$. As shown in Figure 5, radical 19 has four possible subsequent reaction pathways. The potential energy profile along reaction pathways for the homolytic cleavage of $\mathrm{O}-\mathrm{CH}_{3}$ bond is shown in Figure 6 .

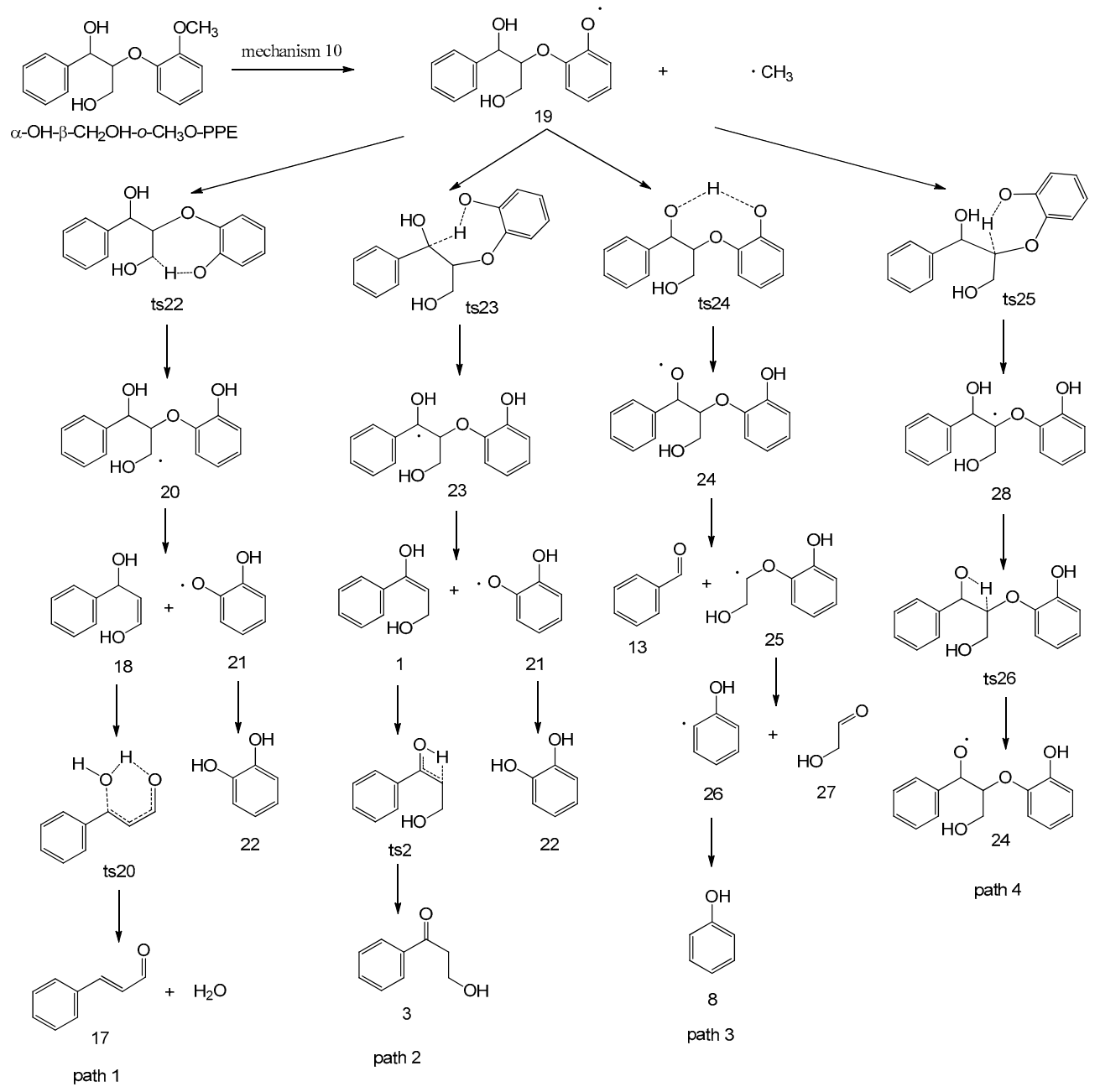

Figure 5. Possible reaction pathways based on $\mathrm{O}-\mathrm{CH}_{3}$ bond homolytic cleavage of $\alpha-\mathrm{OH}-\beta-\mathrm{CH}_{2} \mathrm{OH}-o-\mathrm{CH}_{3} \mathrm{O}-\mathrm{PPE}$.

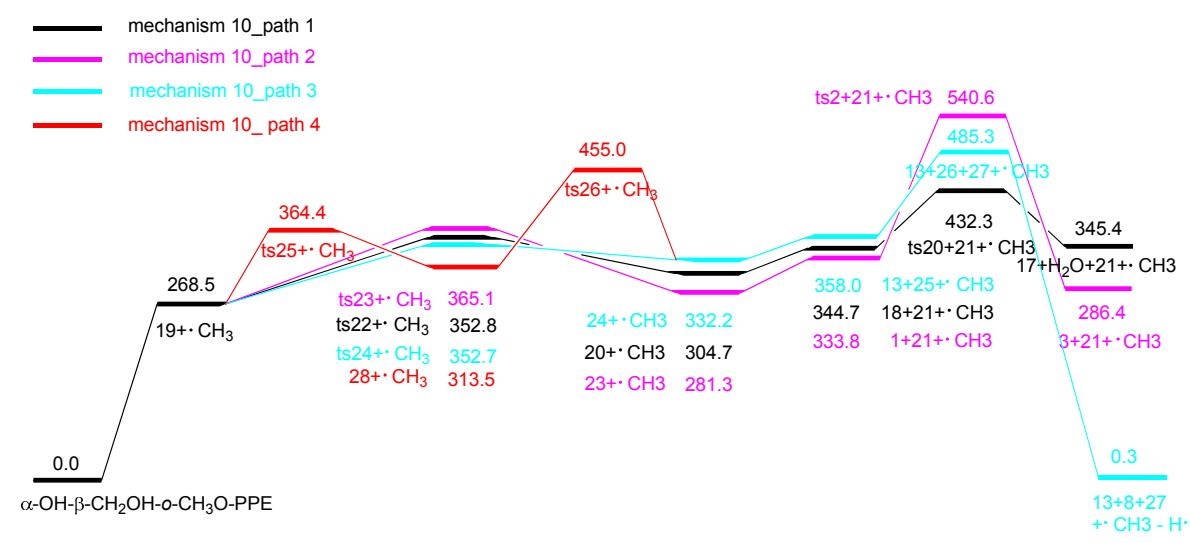

Figure 6. Potential energy profile along reaction pathways for the homolytic cleavage of $\mathrm{O}-\mathrm{CH}_{3}$ bond. 
In path 1 , the $\mathrm{H}$ atom at $\mathrm{C}_{\gamma}$ position of radical 19 transfers to phenoxy radical through a seven-membered ring transition state ts 22 to form radical 20 with an energy barrier of $84.3 \mathrm{~kJ} / \mathrm{mol}$. Radical 20 undergoes further $\mathrm{C}_{\beta}-\mathrm{O}$ bond homolytic cleavage to form intermediate $\mathbf{1 8}$ and radical 21 with an energy barrier of $40.0 \mathrm{~kJ} / \mathrm{mol}$. Radical 21 will couple with free $\mathrm{H}$ radical to form hydrogenated product 22 (catechol). Intermediate 18 will transform into product 17 (3-phenylacrylaldehyde) following the reaction pathway in concerted mechanism 8 .

In path 2, the $\mathrm{H}$ atom at $\mathrm{C}_{\alpha}$ position of radical 19 transfers to phenoxy radical through a seven-membered ring transition state ts 23 to form radical 23 with an energy barrier of $96.6 \mathrm{~kJ} / \mathrm{mol}$. Radical 23 further undergoes $\mathrm{C}_{\beta}-\mathrm{O}$ bond homolytic cleavage to generate intermediate $\mathbf{1}$ and radical 21 with an energy barrier of $52.5 \mathrm{~kJ} / \mathrm{mol}$. Intermediate 1 will transform into product 3 (3-hydroxy-1-phenylpropan-1-one) following the reaction pathway in concerted mechanism 1.

In path 3 , the $\mathrm{H}$ atom of the hydroxyl group at $\mathrm{C}_{\alpha}$ position of radical 19 transfers to phenoxy radical through an eight-membered ring transition state ts24 to form radical 24 with an energy barrier of $84.2 \mathrm{~kJ} / \mathrm{mol}$. Then radical 24 undergoes $C_{\alpha}-C_{\beta}$ bond homolytic cleavage to form product 13 (benzaldehyde) and radical 25 with an energy barrier of $25.8 \mathrm{~kJ} /$ mol. Radical 25 continues to undergo $\mathrm{C}_{\text {aromatic }}-\mathrm{O}$ bond homolytic cleavage to form radical 26 and product 27 (hydroxyacetaldehyde) with an energy barrier of $127.3 \mathrm{~kJ} / \mathrm{mol}$. Radical 26 will combine with free $\mathrm{H}$ radical to form hydrogenated product 8 (phenol).

In path 4, radical 19 undergoes intramolecular hydrogen transfer reactions through two consecutive transition states ts 25 and ts 26 to form radical 24 with energy barriers of $95.9 \mathrm{~kJ} / \mathrm{mol}$ and $141.5 \mathrm{~kJ} / \mathrm{mol}$, respectively. Radical 24 will follow path 3 to undergo subsequent reactions. Comparing the energy barriers to form radical 24 in paths 3 and 4, path 3 is superior to path 4 due to its lower energy barrier.

The above four subsequent pyrolysis pathways based on homolytic mechanism 10 are competitive with each other. As shown in Figure 6, the energy barriers of ts22 and ts24 are close and lower than those of ts 23 and ts 25 . Hence, the major pyrolytic products based on mechanism 10 include $\mathbf{1 7}$ (3-phenylacrylaldehyde), 22 (catechol), 13 (benzaldehyde), 8 (phenol) and 27 (hydroxyacetaldehyde). Products 17 and 13 can also be formed through concerted mechanisms 8 and 6, respectively. In comparison of concerted mechanism 8 and homolytic mechanism 10, product 17 is easily formed from concerted mechanism 8 , while product $\mathbf{1 3}$ is easily formed from homolytic mechanism 10.

In homolytic mechanism $11, \alpha-\mathrm{OH}-\beta-\mathrm{CH}_{2} \mathrm{OH}-o-\mathrm{CH}_{3} \mathrm{O}-\mathrm{PPE}$ undergoes $\mathrm{C}_{\beta}-\mathrm{O}$ bond homolytic cleavage to form radicals 29 and 30 with an energy barrier of $288.9 \mathrm{~kJ} / \mathrm{mol}$. The subsequent pyrolysis pathways of radicals $\mathbf{2 9}$ and $\mathbf{3 0}$ are shown in Figure 7, and the corresponding potential energy profile is depicted in Figure 8. Radical 29 has four possible following pathways. It loses the hydroxyl groups at $C_{\gamma}$ and $C_{\alpha}$ positions to form products 31 (1-phenylprop-2-en-1-ol) and 32 (3-phenylprop-2-en-1-ol) with energy barriers of $130.0 \mathrm{~kJ} / \mathrm{mol}$ and $123.2 \mathrm{~kJ} / \mathrm{mol}$, respectively. Or it undergoes dehydrogenation reactions at $C_{\alpha}$ and $C_{\gamma}$ positions to form intermediates 1 and 18 with energy barriers of $130.5 \mathrm{~kJ} / \mathrm{mol}$ and $141.5 \mathrm{~kJ} / \mathrm{mol}$, respectively. They will follow the reaction pathways in concerted mechanisms 1 and 8 to form products 3 (3-hydroxy-1-phenylpropan-1-one) and $\mathbf{1 7}$ (3-phenylacrylaldehyde). As shown in Figure 8 , the above four pathways of radical 29 are competitive with each other, among which path 2 has the lowest energy barrier to form product 32 (3-phenylprop-2-en-1-ol).

Radical 30 can undergo a series of reactions to form product 36 (2-hydroxybenzaldehyde). It firstly undergoes intramolecular hydrogen transfer reaction through a six-membered ring transition state ts27 to form radical 33 with an energy barrier of $102.9 \mathrm{~kJ} / \mathrm{mol}$. Radical 33 then goes through C-O shift reaction via two consecutive transition states ts28 and ts29 to form radical 35 with energy barriers of $73.2 \mathrm{~kJ} / \mathrm{mol}$ and $7.2 \mathrm{~kJ} / \mathrm{mol}$, respectively. Radical 35 finally undergoes dehydrogenation reaction to form product 36 (2-hydroxybenzaldehyde) with an energy barrier of $52.6 \mathrm{~kJ} / \mathrm{mol}$. Hence, the major pyrolytic products based on homolytic mechanism 11 (paths 2 and 5) are 32 (3-phenylprop-2-en-1-ol) and 36 (2-hydroxybenzaldehyde). 


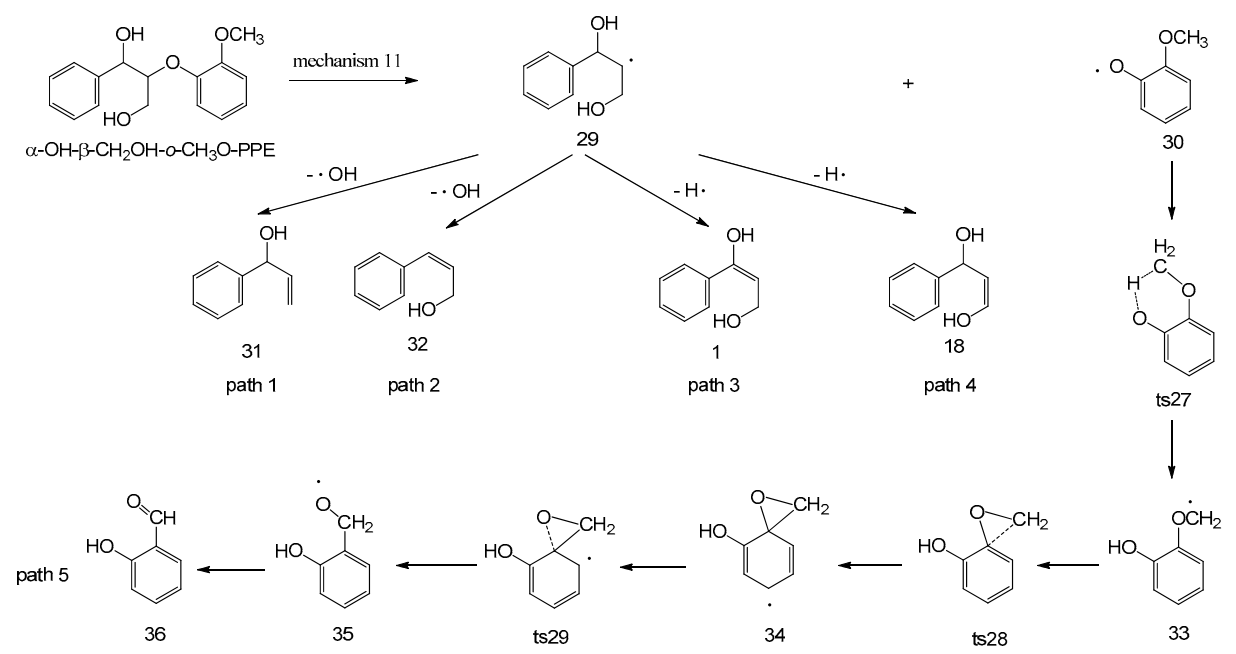

Figure 7. Possible reaction pathways based on $\mathrm{C}_{\beta}-\mathrm{O}$ bond homolytic cleavage of $\alpha-\mathrm{OH}-\beta-\mathrm{CH}_{2} \mathrm{OH}-o-\mathrm{CH}_{3} \mathrm{O}-\mathrm{PPE}$.

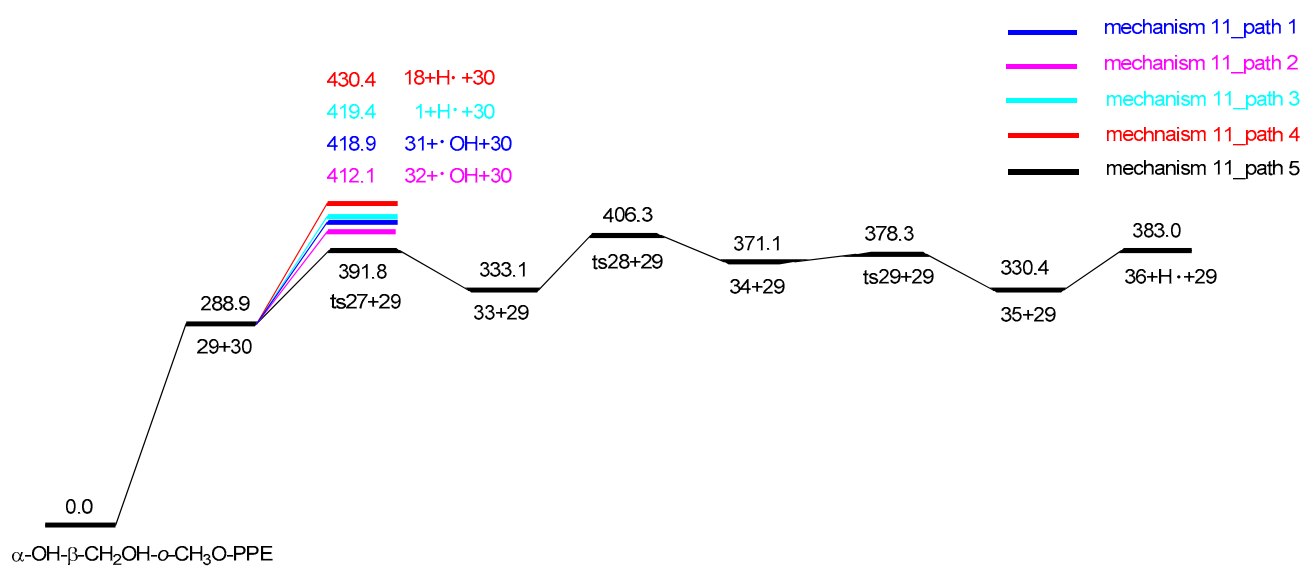

Figure 8. Potential energy profile along reaction pathways for the homolytic cleavage of $\mathrm{C}_{\beta}-\mathrm{O}$ bond (unit: $\mathrm{kJ} / \mathrm{mol}$ ).

\subsubsection{Summary}

Based on the energy barriers of the above 11 pyrolysis mechanisms of $\alpha-\mathrm{OH}-\beta$ $\mathrm{CH}_{2} \mathrm{OH}-o-\mathrm{CH}_{3} \mathrm{O}-\mathrm{PPE}$, their competitiveness will follow this order, i.e., mechanism $2>$ mechanism $3>$ mechanism $5>$ mechanism $8>$ mechanism $1>$ mechanism $7>$ mechanism $9>$ mechanism $10>$ mechanism $11>$ mechanism $4>$ mechanism 6 . Among the unimolecular decomposition pathways of $\alpha-\mathrm{OH}-\beta-\mathrm{CH}_{2} \mathrm{OH}-o-\mathrm{CH}_{3} \mathrm{O}-\mathrm{PPE}$, most of the concerted mechanisms are superior to homolytic mechanisms except for mechanism 6 . The major pyrolytic products based on concerted mechanisms include 2 (2-methoxyphenol), 3 (3-hydroxy-1-phenylpropan-1-one), 8 (phenol), 10 (1-methoxy-2-(styryloxy)benzene) and 17 (3-phenylacrylaldehyde). While the pyrolytic products based on $\mathrm{O}-\mathrm{CH}_{3}$ and $\mathrm{C}_{\beta}-\mathrm{O}$ bond homolytic mechanisms include 13 (benzaldehyde), 22 (catechol), 32 (3-phenylprop-2-en-1-ol) and 36 (2-hydroxybenzaldehyde). Product 2 (2-methoxyphenol) is the most abundant product generated from most of the concerted mechanisms with relatively low energy barriers. In addition, radical $\mathbf{3 0}$ formed from $\mathrm{C}_{\beta}-\mathrm{O}$ bond homolytic mechanism can also combine with free $\mathrm{H}$ radical and undergo $\mathrm{H}$-abstraction to form product 2 (2-methoxyphenol) [20,23,30]. It agrees with the results obtained by He et al. [22] and Jiang et al. [31]. They conducted pyrolysis experiments on a $\beta-O-4$ type lignin dimer model compound (guaiacylglycerol- $\beta$-guaiacyl ether) which has same functional groups on the alkyl side chain and aromatic ring near the ether bond. 
They found that 2-methoxyphenol was the major product while the other products were in low yields. These experimental results firmly confirm that the proposed pyrolysis model in Figure 1 is reasonable and reliable.

The integrated pyrolysis mechanisms of the other four $\beta-O-4$ type lignin model compounds PPE, $\alpha$-OH-PPE, $\beta-\mathrm{CH}_{2} \mathrm{OH}-\mathrm{PPE}$ and $o-\mathrm{CH}_{3} \mathrm{O}-\mathrm{PPE}$ are depicted in the Supplementary Materials (Figures S1-S4) based on the proposed pyrolysis model in Figure 1. Pyrolysis of PPE may follow mechanisms 1,2 and 11 to decompose, and their competitiveness is in the order of mechanism $2>$ mechanism 1 $>$ mechanism 11. $\alpha$-OH-PPE may undergo pyrolysis reactions through mechanisms 1, 2, 4, 5, 6 and 11 , and their competitiveness follows the order of mechanism $2>$ mechanism $1>$ mechanism $4>$ mechanism $11>$ mechanism $5>$ mechanism $6 . \beta-\mathrm{CH}_{2} \mathrm{OH}-\mathrm{PPE}$ may follow five pyrolysis mechanisms to decompose, whose competitiveness order is mechanism $2>$ mechanism $1>$ mechanism $7>$ mechanism $8>$ mechanism 11. $o-\mathrm{CH}_{3} \mathrm{O}-\mathrm{PPE}$ also has five possible pyrolysis mehanisms with the competitiveness order of mechanism $2>$ mechanism $3>$ mechanism $1>$ mechanism $10>$ mechanism 11 . It is important to note that the major pyrolytic products of the four model compounds obtained through DFT calculations shown in the Supplementary Materials agree well with the experimental results $[18,19,29,31]$, which futher confirms the validity of the pyrolysis model. Based on the results, a similar conclusion can be drawn that most of the concerted mechanisms are prior to homolytic mechanisms, except for mechanism 6 . The above results clearly illustrate that based on the pyrolysis model proposed in Figure 1, the pyrolysis mechanisms for different $\beta-O-4$ type lignin dimer model compounds basically follow certain specific rules, but different functional groups will affect the pyrolytic product distribution. Hence, the pyrolysis model in Figure 1 can be used to predict the pyrolytic pathways and products.

\section{Discussion}

According to the above analyses, concerted mechanisms and homolytic mechanisms are coexisting in the pyrolysis process of $\beta-O-4$ type lignin dimer model compounds. Moreover, concerted mechanisms are generally prior to homolytic mechanisms, indicating concerted mechanisms are dominant for the pyrolysis process. Mechanisms 1, 2 and 11 are fundamental for all $\beta-O-4$ type lignin dimer model compounds and their competitiveness follows the order of mechanism $2>$ mechanism $1>$ mechanism 11, which is irrelevant to the hydroxyl, hydroxymethyl and methoxyl groups. In consideration of the effects of functional groups, the competitiveness of the proposed 11 pyrolysis mechanisms for different $\beta-O-4$ type lignin dimers can be concluded in the order of mechanism $2>$ mechanism $3>$ mechanism $1>$ mechanism $7>$ mechanism $9>$ mechanism $10>$ mechanism $11>$ mechanism 6, wherein mechanisms 4, 5 and 8 can hardly be ranked because their competitiveness is dramatically affected by the functional groups on the aromatic ring and alkyl side chain. Among these mechanisms, mechanism 3 is quite competitive with mechanism 2 (retro-ene fragmentation) which is considered as the dominant pyrolysis mechanism of substituted $\beta-O-4$ model compounds $[21,23]$. Mechanism $10\left(\mathrm{O}-\mathrm{CH}_{3}\right.$ bond homolytic cleavage $)$ will supersede mechanism 11 $\left(\mathrm{C}_{\beta}-\mathrm{O}\right.$ bond homolytic cleavage $)$ to be the optimal homolytic mechanism. Mechanism 6 can hardly take place due to its high energy barrier.

The application of the proposed pyrolysis model ultimately offers a theoretical basis to predict the pyrolytic pathways and the formed products. PPE is the simplest $\beta-O-4$ type lignin dimer model compound [32], and the major pyrolytic products are styrene and phenol, which has been confirmed in this study as well as previous studies $[29,33,34]$. In the presence of functional groups on the alkyl side chain and aromatic ring, the pyrolytic product distribution will be changed, but have regularity. Pyrolysis of the methoxyl-substituted PPEs mainly proceeds through concerted mechanisms (mechanisms 1, 2, 5, 7 and 8) to produce 2-methoxyphenol (or 2,6-dimethoxyphenol) as one of the dominant pyrolytic products. Furthermore, another dominant product 2-hydroxybenzaldehyde (or 2-hydroxy-3-methoxybenzaldehyde) can be formed from a key intermediate methoxyphenoxy (or 2,6-dimethoxyphenoxy) radical through a series of reaction steps [2,29] shown in Figure 7 (mechanism 11). The $\alpha$-hydroxyl-substituted PPEs may undergo dehydration reactions to form the 
compounds containing an unsaturated $\mathrm{C}=\mathrm{C}$ double bond through mechanisms 4 . These compounds are easy to transform into macromolecular compounds and coke through polymerization [35], which may be one of the possible reasons for high char yield during lignin pyrolysis process. In addition, the major pyrolytic products from pyrolysis of $\alpha$-hydroxyl-substituted PPEs have a $\mathrm{C}=\mathrm{O}$ feature structure at $\mathrm{C}_{\alpha}$ position. Similarly, the major pyrolytic products formed from pyrolysis of $\beta$-hydroxymethyl-substituted PPEs also have a $\mathrm{C}=\mathrm{O}$ feature structure at $\mathrm{C}_{\gamma}$ position. In the following studies, the pyrolysis models for other lignin structures containing oxidized substituents and $\alpha-O-4$, $4-O-5, \beta-1, \beta-5$ or $5-5$ linkages will be investigated to comprehensively understand the lignin pyrolysis process, which can provide theoretical guidance for developing efficient selective pyrolysis techniques.

\section{Calculation Methods}

All calculations were conducted in Gaussian 09 suite of programs [36]. The geometries of reactants, intermediates, transition states and products were optimized by using hybrid density functional M06-2X and the $6-31+G(d, p)$ basis set, followed by frequency calculations. To simulate the real pyrolysis condition, the thermodynamic parameters at typical pyrolysis temperature and pressure ( $873 \mathrm{~K}$ and $101 \mathrm{kPa}$ ) were obtained by frequency analyses. The transition states were located by TS method in which only the initial guesses of the transition states were used without using the corresponding initial guesses of reactants and products. Furthermore, intrinsic reaction coordinate (IRC) calculations were conducted to confirm the corresponding reactants, transition states and products on the same potential energy surface (PES). The reactants, intermediates and products had no imaginary frequency, while the transition states had only one imaginary frequency. Activation energies for concerted reactions were estimated with the energy differences between transition states and reactants. While for homolytic cleavage reactions, transition states were very difficult to find because there were no saddle points on the PES, the BDE was generally regarded as approximation to activation energy for comparison [13,34,37].

\section{Conclusions}

A pyrolysis model containing 11 initial pyrolysis mechanisms (mechanisms 1-11) for $\beta-O-4$ type lignin dimers is proposed which comprehensively considers the effects of functional groups (hydroxyl, hydroxymethyl and methoxyl) on the alkyl side chain and aromatic ring. Based on the pyrolysis model, the integrated pyrolysis mechanisms of five specific $\beta-\mathrm{O}-4$ type lignin dimer model compounds are investigated by DFT calculations. The results indicate that among the unimolecular decomposition pathways, concerted mechanisms and homolytic mechanisms are coexisting, while concerted mechanisms are predominant and mainly responsible for the pyrolysis process. Mechanisms 1,2 and 11 are three basic mechanisms of all $\beta-O-4$ type lignin dimers and their competitiveness order remains invariable (mechanism $2>$ mechanism $1>$ mechanism 11) regardless of functional groups. The competitiveness of the proposed 11 pyrolysis mechanisms follows the order of mechanism 2 $>$ mechanism $3>$ mechanism $1>$ mechanism $7>$ mechanism $9>$ mechanism $10>$ mechanism $11>$ mechanism 6, wherein mechanisms 4,5 and 8 can hardly be ranked in view of the effects of functional groups. Combining previous experimental studies, it can be concluded that the proposed pyrolysis model is reasonable and reliable.

Supplementary Materials: Supplementary materials can be found at www.mdpi.com/1422-0067/18/11/2364/s1.

Acknowledgments: The authors thank the National Natural Science Foundation of China $(51576064,51676193)$, Beijing Nova Program (Z171100001117064), Beijing Natural Science Foundation (3172030), Foundation of Stake Key Laboratory of Coal Combustion (FSKLCCA1706) and Fundamental Research Funds for the Central Universities (2017MS071, 2016YQ05) for financial support.

Author Contributions: Xiaoyan Jiang and Qiang Lu conducted the density functional theory (DFT) calculations, data analysis and writing. Bin Hu and Ji Liu assisted with data analysis. Changqing Dong, Yongping Yang and the above authors reviewed, contributed to the revising, and agreed to the article's content.

Conflicts of Interest: The authors declare no conflict of interest. 


\section{References}

1. Zakzeski, J.; Bruijnincx, P.C.A.; Jongerius, A.L.; Weckhuysen, B.M. The catalytic valorization of lignin for the production of renewable chemicals. Chem. Rev. 2010, 110, 3552-3599. [CrossRef] [PubMed]

2. Kawamoto, H. Lignin pyrolysis reactions. J. Wood Sci. 2017, 63, 117-132. [CrossRef]

3. Mu, W.; Ben, H.; Ragauskas, A.; Deng, Y. Lignin pyrolysis components and upgrading-Technology review. Bioenergy Res. 2013, 6, 1183-1204. [CrossRef]

4. Azadi, P.; Inderwildi, O.R.; Farnood, R.; King, D.A. Liquid fuels, hydrogen and chemicals from lignin: A critical review. Renew. Sustain. Energy Rev. 2013, 21, 506-523. [CrossRef]

5. Parthasarathi, R.; Romero, R.A.; Redondo, A.; Gnanakaran, S. Theoretical study of the remarkably diverse linkages in lignin. J. Phys. Chem. Lett. 2011, 2, 2660-2666. [CrossRef]

6. Kim, S.; Chmely, S.C.; Nimlos, M.R.; Bomble, Y.J.; Foust, T.D.; Paton, R.S.; Beckham, G.T. Computational study of bond dissociation enthalpies for a large range of native and modified lignins. J. Phys. Chem. Lett. 2011, 2, 2846-2852. [CrossRef]

7. Asatryan, R.; Bennadji, H.; Bozzelli, J.W.; Ruckenstein, E.; Khachatryan, L. Molecular products and fundamentally based reaction pathways in the gas-phase pyrolysis of the lignin model compound $p$-coumaryl alcohol. J. Phys. Chem. A 2017, 121, 3352-3371. [CrossRef] [PubMed]

8. Sharma, A.; Pareek, V.; Zhang, D. Biomass pyrolysis-A review of modelling, process parameters and catalytic studies. Renew. Sustain. Energy Rev. 2015, 50, 1081-1096. [CrossRef]

9. Bridgwater, A.V. Review of fast pyrolysis of biomass and product upgrading. Biomass Bioenergy 2012, 38, 68-94. [CrossRef]

10. Collard, F.X.; Blin, J. A review on pyrolysis of biomass constituents: Mechanisms and composition of the products obtained from the conversion of cellulose, hemicelluloses and lignin. Renew. Sustain. Energy Rev. 2014, 38, 594-608. [CrossRef]

11. Amen-Chen, C.; Pakdel, H.; Roy, C. Production of monomeric phenols by thermochemical conversion of biomass: A review. Bioresour. Technol. 2001, 79, 277-299. [CrossRef]

12. Wang, Q.; Guan, S.; Shen, D. Experimental and kinetic study on lignin depolymerization in water/formic acid system. Int. J. Mol. Sci. 2017, 18, 2082. [CrossRef] [PubMed]

13. Huang, J.; Liu, C.; Wu, D.; Tong, H.; Ren, L. Density functional theory studies on pyrolysis mechanism of 3-O-4 type lignin dimer model compound. J. Anal. Appl. Pyrolysis 2014, 109, 98-108. [CrossRef]

14. Jiang, X.Y.; Lu, Q.; Ye, X.N.; Hu, B.; Dong, C.Q. Experimental and theoretical studies on the pyrolysis mechanism of $\beta$-1-type lignin dimer model compound. BioResources 2016, 11, 6232-6243. [CrossRef]

15. Wang, S.; Ru, B.; Dai, G.; Shi, Z.; Zhou, J.; Luo, Z.; Ni, M.; Cen, K. Mechanism study on the pyrolysis of a synthetic $\beta-O-4$ dimer as lignin model compound. Proc. Combust. Inst. 2017, 36, 2225-2233. [CrossRef]

16. Liu, C.; Wilson, A.K. Cleavage of the $\beta-O-4$ linkage of lignin using group 8 pincer complexes: A DFT study. J. Mol. Catal. A Chem. 2015, 399, 33-41. [CrossRef]

17. Younker, J.M.; Beste, A.; Buchanan, A.C. Computational study of bond dissociation enthalpies for substituted ß-O-4 lignin model compounds. ChemPhysChem 2011, 12, 3556-3565. [CrossRef] [PubMed]

18. Zhang, J.J.; Jiang, X.Y.; Ye, X.N.; Chen, L.; Lu, Q.; Wang, X.H.; Dong, C.Q. Pyrolysis mechanism of a $\beta-O-4$ type lignin dimer model compound. J. Therm. Anal. Calorim. 2016, 123, 501-510. [CrossRef]

19. Chen, L.; Ye, X.; Luo, F.; Shao, J.; Lu, Q.; Fang, Y.; Wang, X.; Chen, H. Pyrolysis mechanism of $\beta-O-4$ type lignin model dimer. J. Anal. Appl. Pyrolysis 2015, 115, 103-111. [CrossRef]

20. Beste, A.; Buchanan, A.C., III. Substituent effects on the reaction rates of hydrogen abstraction in the pyrolysis of phenethyl phenyl ethers. Energy Fuels 2010, 24, 2857-2867. [CrossRef]

21. Elder, T.; Beste, A. Density functional theory study of the concerted pyrolysis mechanism for lignin models. Energy Fuels 2014, 28, 5229-5235. [CrossRef]

22. He, T.; Zhang, Y.; Zhu, Y.; Wen, W.; Pan, Y.; Wu, J.; Wu, J. Pyrolysis mechanism study of lignin model compounds by synchrotron vacuum ultraviolet photoionization mass spectrometry. Energy Fuels 2016, 30, 2204-2208. [CrossRef]

23. Wang, M.; Liu, C. Theoretic studies on decomposition mechanism of $o$-methoxy phenethyl phenyl ether: Primary and secondary reactions. J. Anal. Appl. Pyrolysis 2016, 117, 325-333. [CrossRef]

24. Kawamoto, H.; Horigoshi, S.; Saka, S. Effects of side-chain hydroxyl groups on pyrolytic $\beta$-ether cleavage of phenolic lignin model dimer. J. Wood Sci. 2007, 53, 268-271. [CrossRef] 
25. Kawamoto, H.; Nakamura, T.; Saka, S. Pyrolytic cleavage mechanisms of lignin-ether linkages: A study on p-substituted dimers and trimers. Holzforschung 2008, 62, 50-56. [CrossRef]

26. Kawamoto, H.; Ryoritani, M.; Saka, S. Different pyrolytic cleavage mechanisms of $\beta$-ether bond depending on the side-chain structure of lignin dimers. J. Anal. Appl. Pyrolysis 2008, 81, 88-94. [CrossRef]

27. Kawamoto, H.; Saka, S. Role of side-chain hydroxyl groups in pyrolytic reaction of phenolic $\beta$-ether type of lignin dimer. J. Wood Chem. Technol. 2007, 27, 113-120. [CrossRef]

28. Britt, P.F.; Kidder, M.K.; Buchanan, A.C., III. Oxygen substituent effects in the pyrolysis of phenethyl phenyl ethers. Energy Fuels 2007, 21, 3102-3108. [CrossRef]

29. Britt, P.F.; Buchanan, A.C.; Cooney, M.J.; Martineau, D.R. Flash vacuum pyrolysis of methoxy-substituted lignin model compounds. J. Org. Chem. 2000, 65, 1376-1389. [CrossRef] [PubMed]

30. Elder, T. A computational study of pyrolysis reactions of lignin model compounds. Holzforschung 2010, 64, 435-440. [CrossRef]

31. Jiang, W.; Wu, S.; Lucia, L.A.; Chu, J. A comparison of the pyrolysis behavior of selected $\beta-O-4$ type lignin model compounds. J. Anal. Appl. Pyrolysis 2017, 125, 185-192. [CrossRef]

32. Beste, A.; Buchanan, A.C., III. Kinetic simulation of the thermal degradation of phenethyl phenyl ether, a model compound for the $\beta-O-4$ linkage in lignin. Chem. Phys. Lett. 2012, 550, 19-24. [CrossRef]

33. Huang, X.; Liu, C.; Huang, J.; Li, H. Theory studies on pyrolysis mechanism of phenethyl phenyl ether. Comput. Theor. Chem. 2011, 976, 51-59. [CrossRef]

34. Jarvis, M.W.; Daily, J.W.; Carstensen, H.H.; Dean, A.M.; Sharma, S.; Dayton, D.C.; Robichaud, D.J.; Nimlos, M.R. Direct detection of products from the pyrolysis of 2-phenethyl phenyl ether. J. Phys. Chem. A 2011, 115, 428-438. [CrossRef] [PubMed]

35. Nakamura, T.; Kawamoto, H.; Saka, S. Condensation reactions of some lignin related compounds at relatively low pyrolysis temperature. J. Wood Chem. Technol. 2007, 27, 121-133. [CrossRef]

36. Frisch, M.J.; Trucks, G.W.; Schlegel, H.B.; Scuseria, G.E.; Robb, M.A.; Cheeseman, J.R.; Scalmani, G.; Barone, V.; Mennucci, B.; Petersson, G.A.; et al. Gaussian 09; Revision D.01; Gaussian, Inc.: Wallingford, CT, USA, 2013.

37. Huang, J.; He, C. Pyrolysis mechanism of $\alpha-O-4$ linkage lignin dimer: A theoretical study. J. Anal. Appl. Pyrolysis 2015, 113, 655-664. [CrossRef]

(C) 2017 by the authors. Licensee MDPI, Basel, Switzerland. This article is an open access article distributed under the terms and conditions of the Creative Commons Attribution (CC BY) license (http:/ / creativecommons.org/licenses/by/4.0/). 